\title{
Corpo, trabalho e prazer: as práticas de prostituição em cadastros policiais ${ }^{1}$
}

Fernanda Surubi Fernandes (UNEMAT) Olimpia Maluf Souza (UNEMAT)

\section{Resumo}

Este artigo tem como objetivo analisar a relação corpo-trabalho-prazer em práticas de prostituição. Questionamos o que éo trabalho na relação como corpo, o que é o corpo na relação com o trabalho e com o prazer? Nessa direção, pretendemos neste estudo abordar a teoria da Análise de Discurso de linha francesa, que tem como objeto teórico o discurso, no qual encontramos as marcas de ruptura que nos permitirão compreender, através dos gestos de interpretação, como o sentido faz sentido.

Palavras-chaves: prostituição; prazer; profissão; corpo.

Este artigo é um recorte da dissertação de Mestrado: Castidade e Luxúria: a constituição da imagem feminina nos cadastros policiais - UNEMAT/2012. 


\section{Introdução}

Atualmente, no Brasil, há lutas que buscam a legalização da prostituição como profissão. No entanto, ainda é uma questão de grande complexidade, pois a dificuldade dessa legalização passa por interditos na relação do trabalho com o corpo produzindo sentidos na atualidade. Nessa direção, parece-nos necessário compreender o trabalho na relação com o corpo e o corpo na relação com o trabalho e com o prazer. No caso da prostituta, o corpo é seu instrumento de trabalho, mas, ao mesmo tempo, a moral religiosa o institui como "templo sagrado", assim, esse sentido produz, para a prostituta/prostituição, efeitos de que sua atividade de meretriz transgride o lugar instituído pela moral social cristã. Fazemos uso do corpo para o trabalho - trabalho braçal, trabalho intelectual, etc. -, pois é ele que nos permite produzir, porém, a meretriz, ao usar do corpo para atividades relacionadas ao sexo, foge ao que é determinado pela moral social como trabalho honesto, uma vez que o corpo da prostituta é usado para sentir/dar prazer.

Essa situação produz problemas em relação aos direitos e deveres das prostitutas e coloca em funcionamento toda uma memória constitutiva da prostituta/prostituição que é marcada de forma negativa. São sentidos que foram construídos em relação à sexualidade, aos vários imaginários sociais sobre a mulher, à prostituta na história produzindo efeitos que marcam o estigma social.

Nessa direção, no batimento entre a paráfrase e a polissemia, a prostituição alcançou status de ocupação, pela Classificação Brasileira de Ocupações (CBO), mas ainda não se coloca como profissão, no Brasil, apesar de haver, já há muito tempo, vários projetos de lei com tal finalidade.

De todo o modo, são as discussões sobre a profissionalização da prostituição que possibilitam, nos cadastros policiais dos anos 60 e 70, na cidade de Cáceres-MT², a compreensão de uma dualidade que se tornou constitutiva dessa atividade, uma vez que os registros ora marcam a prostituição como profissão ora como ócio, prazer, luxúria, caracterizando-a como um "desvio".

\section{A construção dos sentidos: o corpo na relação trabalho $x$ prazer}

Foucault (2008, p. 117) ao falar da docilidade dos corpos, nos mostra a dominação do corpo como uma forma de poder:

Houve, durante a época clássica, uma descoberta do corpo como objeto e alvo de poder. Encontraríamos facilmente sinais dessa grande atenção dedicada então ao corpo - ao corpo que se manipula, se modela, se treina, que obedece, responde, se torna hábil ou cujas forças se multiplicam.

Esse corpo modelado, controlado, põe em funcionamento uma memória sobre a sexualidade insubmissa, ou seja, a prosti- 
tuição se realiza pelo uso do corpo para o prazer, não exercendo o que se espera de um corpo dócil, isto é, “[...] um corpo que pode ser submetido, que pode ser utilizado, que pode ser transformado e aperfeiçoado" (op.cit, p.118). Essa docilização dos corpos leva-nos a questionar como é constituído, nesse espaço disciplinar, a prostituta e a prostituição, pois, para Foucault (2008, p. 123), há “[...] lugares determinados [que] se definem para satisfazer não só a necessidade de vigiar, de romper as comunicações perigosas, mas também de criar um espaço útil". Um funcionamento, segundo o autor, presente nos hospitais, nos quartéis e nas escolas, cuja tentativa de controlar o ser humano através do corpo, através do trabalho, suprime a sexualidade, exacerba as regras e faz funcionar valores morais.

Nessa relação, o corpo é voltado somente para o trabalho, é como se não houvesse tempo para o não fazer nada, assim, os corpos ociosos são submetidos às regras e, como tais regras não podem parar, tornam-se corpos úteis para o trabalho, mas somente para isso, pois com a submissão freia-se também qualquer ato que o faça mudar ou pensar nas relações de forças de trabalho, uma vez que se trata de extrair dos corpos sempre as forças mais úteis. Segundo Dhoquois (2003, p. 43)

[...] O corpo pode ser usado e coagido não só pelas condições de trabalho como também pela primazia dos interesses da empresa sobre os do trabalhador. O corpo deste está muito envolvido com seu dever de obediência. O corpo laborioso é um corpo submisso.

Esse funcionamento da sociedade disciplinar nos faz pensar no trabalho da prostituta ou na prostituição como trabalho, pois, nesta sociedade, a prostituição vai se colocar em um outro lugar, o lugar do silêncio constitutivo, que se instala historicamente pela opressão e, ao mesmo tempo, pela resistência. Nesse funcionamento, ao se tentar oprimir o trabalho da prostituta/prostituição, o que se produz como efeito são modos de resistência, que vão do enfrentamento absoluto à desobediência silenciosa.

Nos modos de opressão pelo Estado, o corpo é tomado como um meio de controle dos sujeitos, no entanto, a prostituta/ prostituição parece se colocar na contramão desse processo, pois o corpo, que é um objeto de controle, de manipulação pela força do Estado, é, no caso da mulher que se prostitui, seu bem, seu material de trabalho, sua mão de obra, o objeto de sua produção. Assim, essa atividade já se constitui na contramão do processo civilizatório, pois, ao usar o corpo como instrumento de trabalho, a prostituta/prostituição é tomada historicamente como sinônimo de vagabundagem, de preguiça, de luxúria. Ou seja, o uso do corpo para o exercício da sua atividade profissional, desqualifica o seu fazer como profissão. Essa contradição marca a constituição da imagem da prostituta através do corpo, que é tomado por ela 
própria como força de trabalho, como objeto de sua produção e pelo poder do Estado como vagabundagem, como ócio, como libertinagem.

Nessa direção, o corpo feminino marca o lugar do privado, do interditado, e ao mesmo tempo, ele é "[...] exibido, apropriado e carregado de significação" (PERROLT, 2003, p. 14). A constituição da imagem da prostituta vai se produzindo, então, através daquilo que aparenta, através do seu corpo, pois a prostituta/prostituição se constitui nesse lugar contraditório de uso do corpo, tanto para obter lucro quanto para propiciar satisfação sexual a outrem. Para Foucault (1979, p. 22), é no corpo que

[...] se encontra o estigma dos acontecimentos passados do mesmo modo que dele nascem os desejos, os desfalecimentos e os erros; nele também eles [os desejos, os desfalecimentos e os erros] se atam e de repente se exprimem, mas nele também eles se desatam, entram em luta, se apagam uns aos outros e continuam seu insuperável conflito.

Ou seja, o corpo é considerado no sentido da configuração biológica da espécie humana, mas também é materialidade significante, é suporte do simbólico. Essa dupla interpretação sobre o corpo nos leva a compreender como a história, através dos fatos, através das marcas no corpo, reclama sentidos (HENRY, 1997).

Desse modo, a teoria discursiva à qual nos filiamos mostra-nos que há, na forma material, vestígios, marcas de ruptura que nos permitirão compreender, analisar, através dos gestos de interpretação, como o sentido faz sentido.

A Análise de Discurso compreende entre seus conceitos a noção de sujeito, que se constitui pela linguagem, enquanto posição-sujeito. Do mesmo modo, compreende a história como processo de produção de sentidos, atravessada pela contradição; e a língua enquanto possibilidade de discurso, como materialidade onde encontramos o discurso, que para Pêcheux (2009) é efeito de sentido entre locutores, ou seja, é um "[...] processo que se desenvolve de múltiplas formas, em determinadas situações sociais" (ORLANDI, 2007b, p. 54). Sendo assim, é o efeito produzido pela inscrição da língua na história e essa inscrição só pode ser vista através da língua, através do texto, enquanto lugar de materialização da ideologia.

Pela Análise de Discurso, portanto, há, na língua e na história, um real, que compreendemos como sendo da ordem do impossível: "[...] não descobrimos, pois, o real: a gente se depara com ele, dá de encontro com ele, o encontra." (PÊCHEUX, 2008, p. 29), ou seja, não é algo já determinado, mas algo que possibilita a produção dos sentidos, porque o sentido não é estático, é construído em determinadas situações e diferentes sujeitos.

Assim, temos a incompletude como o real da lingua, pois, "[...] toda língua é afetada por uma divisão, [...], que se sustenta pela 
existência de um impossível, inscrito na própria ordem da língua" (GADET e PÊCHEUX, 2010, p. 32). Desse modo, a incompletude é a possibilidade de produção dos sentidos, pois sem ela a língua/ linguagem torna-se inconcebível. Nessa direção, Gadet e Pêcheux (2010, p. 30) afirmam que:

Para os que sustentam que a língua trabalha com a existência de uma ordem própria, o real da língua reside naquilo que nela faz Um, a assegura no Mesmo e no Idêntico e a opõe a tudo o que da linguagem cai para fora dela, nesse inferno ininteligível que os Antigos designam pelo termo de "barbarismo": o campo do interdito na linguagem é, assim, estruturalmente produzido pela língua, do interior dela mesma (Grifos nossos).

Desse modo, pensar a língua como unidade faz parte de um imaginário, que permite que os sentidos possam ser determinados, restringidos, um eficaz trabalho da ideologia. Entrementes, todo sentido produzido "[...] é intrinsecamente suscetível de tornar-se outro, diferente de si mesmo, se deslocar discursivamente de seu sentido para derivar para um outro" (PÊCHEUX, 2008, p. 53), ou seja, os sentidos sempre podem vir a ser outros devido a características constitutivas da língua: a incompletude, a falha, o equívoco. Essa concepção teórica considera que a língua não é transparente, sendo necessário um dispositivo que auxilie no acesso a sua materialidade, assim, a sua discursividade.

A Análise de Discurso compreende o real da história, como sendo a contradição, que possibilita a mudança, o deslocamento, quando se tem o impossível, o alhures. Essa concepção teórica considera que a história deve levar em conta o sujeito, e assim, não pode ser tomada como uma simples sucessão de fatos, um relato, mas um acontecimento no discurso, ou seja, um modo de produção de sentidos.

Desse modo, a $\mathrm{AD}$ considera não a história propriamente, mas a historicidade, que se encontra no texto, considera, portanto, não partir da história para o texto, mas do próprio texto, uma vez que, através da "trama de sentidos", a história constitui-se nele.

Nessa direção, a Análise de discurso é vista como um processo de desnaturalização, que busca compreender funcionamento da ideologia, ou seja, busca ver na materialidade como as histórias são mobilizadas. Uma história é, de um lado, fatos, acontecimento, e de outro, é a compreensão desses fatos tomados como acontecimentos. Nesse caso, desnaturalizar os sentidos que estão postos, é compreender que algo pode sempre tomar outros sentidos.

Os traços da memória histórica materializam-se na língua como efeitos de sentido que, no momento da formulação, dada as condições de produção - o contexto imediato e o contexto sócio-histórico - são colocados em funcionamento. O sujeito é posição-sujeito, pois o seu dizer produz sentidos que são sempre postos em relação $a$. 
Desse modo, há sentidos que são cristalizados pela sociedade, mas há também os que são silenciados, fazendo com que haja sentidos que instituem cada palavra - é o que ocorre com a palavra "prostituta" - que, ao ser formulada, aciona um já-dito, um pré-construído, que é colocado em funcionamento por diferentes posições-sujeito marcadas pelos modos de inscrição nessa memória.

A prostituta/prostituição, ao fazer funcionar uma dada memória discursiva, coloca também em funcionamento o sentido de sujeito-de-direito, que é convocado pelas noções de direitos e de deveres que instalam todo sujeito capitalista, pois, para poder se identificar, para poder ser reconhecido socialmente é necessário se assujeitar aos ditames do Estado.

Haroche (1992, p. 51) denomina de "sujeito jurídico da linguística", ou seja, aquele que "[...] se caracteriza por duas propriedades, no limite, contraditórias: uma vontade sem limites e uma submissão sem falhas". Nessas condições, a definição de sujeito-de-direito serve para imputar-lhe a noção de direitos e deveres, o que faz com que pense ser dono de seu dizer e de seu fazer, e, assumindo esse lugar, se assujeite ao Estado para que possa fazer uso dos seus direitos e deveres. Segundo Lagazzi (1988, p. 39), a noção de sujeito-de-direito

[...] é uma noção histórica, que só se concebe à noção de Estado. Ambas - a de sujeito-de-direito e a de Estado - surgiram concomitantes à fundamentação do poder jurídico que, por sua vez, foi (é) decorrência de modificações econômicas que, a partir do século $X$, ocasionaram a passagem gradual do feudalismo para o que se concretizaria, mais tarde, como capitalismo.

Assim, a noção de sujeito-de-direito vem marcar o momento em que o homem se constitui sobre outras determinações, ou seja, deixa de se assujeitar à religião, à Igreja e, passa, através do Direito (que o torna autônomo), a assujeitar-se ao Estado.

De acordo com Lagazzi (op.cit. p. 20) "[...] cada vez mais fortemente o sujeito-de-direito foi se configurando, e hoje a responsabilidade é uma noção constitutiva do caráter humano, da pessoa, do cidadão, sem o que não nos reconheceríamos socialmente". Diante da afirmação da autora, compreendemos que a ideologia, que produz o efeito de evidência de que somos sempre sujeitos sociais com direitos e deveres, se faz por um esquecimento necessário que produz a ilusão de que somos os donos e a origem do nosso dizer, pois o sujeito relaciona-se com o mundo através de um imaginário que se representa pelo simbólico, ou seja, as crenças, as palavras, as próprias relações interpessoais, significam pela ordem simbólica.

Lagazzi (2011) nos mostra como a contradição está marcada no discurso produzindo sentidos. Nessa direção, afirma que a contradição é o que possibilita a mudança, o deslocamento, quando se tem o impossível, o alhures, ou seja, é "[...] a impossibilidade 
da síntese, reiterando a distância entre contradição e oposição" (LAGAZZI, 2011, p. 279).

Assim, a contradição permite a produção de outro sentido que não está marcado pelo já dado, por isso contradição não é o mesmo que oposição. A oposição marca o previsível, não sendo possível produzir outros sentidos, enquanto a contradição é o diferente, é a possibilidade de deslocamento.

Entrementes, Orlandi (2002) nos mostra que há discursos que são interditados de tal forma que não permitem a produção de outros sentidos possíveis, como é o caso da prostituta/prostituição. A produção dos sentidos sobre o imaginário da prostituta circula em torno de aspectos histórico-sociais, que visibilizam os sentidos sobre a prostituição produzindo o preconceito. Para Orlandi (2002, p. 197) o preconceito:

[...] se constitui nas relações sociais, pela maneira como elas se significam e são significadas. Não é um processo consciente e o sujeito não tem acesso ao modo como os preconceitos se constituem nele. Vêm pela filiação a sentidos que ele mesmo nem sabe como se formaram nele.

A AD busca, portanto, a compreensão dos sentidos em suas múltiplas possibilidades. A produção dos sentidos ocorre em funcionamentos discursivos, de modo que os sentidos possam vir a serem outros, ou, nas palavras de Orlandi (2002, p. 197), “[...] os sentidos não podem ser os mesmos", uma vez que dependem das condições de produção nas quais está inserido o dizer.

Pensando assim, chegamos à compreensão de que a produção de sentidos sobre a história da prostituição passa pelo viés das condições históricas e sociais. Incluindo-se os sentidos negativos sobre o imaginário da mulher, de forma geral, e mais especificamente, da meretriz. Esses sentidos negativos estão na base do estigma social, do preconceito que sofreram (e ainda sofrem) as mulheres que eram (e são) meretrizes.

Desse modo, o preconceito impede, segundo Orlandi (2002, p. 198), a produção de sentidos outros, pois restringe-se ao que já está dado. Assim, para a autora, o preconceito está para a ordem da censura ${ }^{3}$, que silencia "[...] sentidos possíveis que [...] não podem ser ditos". O preconceito ocorre, então, na base do silenciamento dos sentidos, na interdição. Nesse caso, certos assuntos são silenciados pela sociedade, pois são ainda considerados tabus, ou seja, passam pelo processo de interdição. A prostituição é um exemplo de tabu, não só ela, mas também toda uma história da sexualidade que foi sendo silenciada por uma sociedade mais conservadora.

Foucault $(1988$, p. 9) nos mostra que, na sexualidade do sé-

Conforme abordado em seu livro As formas do silêncio (ORLANDI, 2007). culo XVII, “[...] ainda vigorava uma certa franqueza. As práticas
não procuravam o segredo; as palavras eram ditas sem reticência excessiva e, as coisas, sem demasiado disfarce; tinha-se com o ilícito uma tolerante familiaridade". Assim, falar de sexo era algo 
tido como comum, não era uma blasfêmia e muito menos algo que somente alguns pudessem falar. Mas, segundo o autor, os discursos sobre o sexo passaram para o "quarto do casal" e para os especialistas, pois somente estes detinham um saber que lhes permitia falar sobre sexo.

Esse funcionamento sobre o sexo nos permite compreender de que forma os sentidos vão sendo constituídos e de que forma o silêncio produz sentidos: através do silenciamento de alguns dizeres para que outros predominem.

Nota-se que atualmente há uma gama de textos, imagens, filmes, sites que falam sobre sexo e sexualidade de várias formas e com vários sentidos. Mas, por outro lado, esse grande número de informações não significa que falar de sexo atualmente deixou de ser tabu, deixou de existir uma repressão sexual. Isso pode ser visualizado pelos meios de censura que existem na atualidade, pois muitos canais de televisão aberta são obrigados a tirar certas cenas do ar ou utilizam um recurso que mitiga as palavras consideradas politicamente incorretas 4 .

Em O Mal-estar na civilização, Freud (1930) nos mostra como os sentidos foram sendo construídos a partir de muitos imaginários sociais, culturais e históricos que perpassam também os dizeres sobre a prostituição.

Nessa direção, para o autor, a própria ideia de civilização, de sociedade, se contrapõe com a de prazer, com a de sexualidade, pois através da sociedade foram se constituindo os modos de se viver, com regras, com direitos e deveres, constituiu-se, assim, o princípio da realidade, que se contrapõe ao princípio do prazer. Para o autor, esses dois princípios fazem parte do ser humano, o que põe em funcionamento, de um lado, o desejo de ser feliz, o imediatismo do prazer, independente de regras, convenções sociais (princípio do prazer), e, de outro, as regras, as normas do como viver em sociedade com o seu igual (princípio da realidade). Essa construção de sentidos perpassa o imaginário sobre a mulher e a prostituição e, dessa forma, sobre a própria sexualidade que constitui todo sujeito. Assim, éinteressante, nesse estudo, perceber que falar sobre a prostituição, sobre a sexualidade ainda é algo que produz preconceito na sociedade atual.

Frente a essas colocações teóricas, nos deteremos na análise (2002, p. 200), “[...] o politicamente correto silencia o fato de que não se trata só de uma questão de boa vontade. Trata-se de explicitar o político". Nessa direção, as palavras consideradas "corretas" servem para representar a moral social presente na atualidade, e, ao mesmo tempo, censurar modos de dizer (outras palavras) sobre questões que ainda são consideradas tabus em nossa sociedade. discursiva dos cadastros policiais que materializam os sentidos sobre a mulher e a prostituição, principalmente na relação trabalho-corpo-prazer, que produzem efeitos na prática da prostituição.

\section{O equívoco constitutivo das/nas práticas de prostituição}

Atualmente, o uso dos termos "puta", "prostituta", "meretriz", entre outros, estão sendo questionados por movimentos que buscam o reconhecimento da prostituição enquanto "[...] uma profissão como outra qualquer" (RODRIGUES, 2009, p. 69). Esses grupos passaram a usar os termos "profissionais do sexo" 
Tais como "Associação das Profissionais do Sexo"; "Rede de Trabajadoras Sexuales de Latinoamerica y el Caribe"; "Trabajadores sexuales argentinas em acción por sus derechos". ou "trabalhadores do sexo". Trata-se, pois, do funcionamento do politicamente correto, que, segundo Orlandi (2002), apenas busca silenciar, apagar os sentidos que estão presentes na sociedade, principalmente em relação ao preconceito. Para a autora, o único modo de mudar os sentidos do uso de determinada palavra é através da mudança das condições de produção dessas palavras, pois só assim elas podem sofrer um deslize, um deslocamento, ou seja, é necessário mudar as relações sociais para que os sentidos deslizem, desloquem e permitam que o preconceito tenha fim.

Desse modo, alguns grupos ${ }^{5}$ que pregam a profissionalização da prostituição não aderem ao uso dos termos "puta", "prostituta", "meretriz", ao contrário, propõem mudanças sobre a forma de denominação da prostituição. Assim, esses novos modos de renomeação - que atendem à demanda atual do politicamente correto - produzem a afirmação do estigma social que esta atividade sofreu/sofre, ao invés de exaltar a prostituta/prostituição enquanto profissão. Ou seja, ao designar a prostituta como "profissional", como "trabalhadora" tenta-se apagar o preconceito que essa atividade produziu ao longo da história. Portanto, ao dizer "somos trabalhadores, somos profissionais" produz-se uma tentativa de silenciamento do estigma social da prostituição para visibilizá-la enquanto "um trabalho como outro qualquer", sem preconceito nenhum. Mas, enquanto os dizeres sobre a prostituta/ prostituição se derem nas condições de produção atuais, a mudança de designação não produzirá nenhum resultado, porque o estigma social continuará produzindo seus efeitos, ou seja, os sentidos das palavras só mudarão se houver condições históricas para isso, ou seja, a proposta de mudança não assegura a adoção e circulação do novo nome.

Nessa relação com o trabalho aparece, então, o equívoco constitutivo das práticas de prostituição, pois toda a contradição presente na relação prostituição x trabalho e corpo - vem investida por questionamentos presentes no nosso dia a dia, na sociedade: circulando, produzindo sentidos. Afinal, o que é trabalho? O que é esse trabalho na relação com o corpo, o que é o corpo na relação com o trabalho e com o prazer?

Há, nas relações sociais, uma insuportabilidade em deixar circular os sentidos sobre o prazer, porque a sexualidade traz para todos os sujeitos um fantasma socialmente insustentável que é o prazer. Historicamente, a relação entre trabalho e prazer é algo inconciliável, principalmente no momento em que a Igreja, como instituição, leva o homem a repudiar o prazer, através da moralidade, atravessando, barrando constantemente a sua relação com a sexualidade.

O preconceito funciona, então, como um modo de dar visibilidade a essas questões, pois faz circular pré-construídos nos quais os dizeres sobre prazer/sexualidade são silenciados, ou seja, 
não se pode falar de prazer, não se pode falar sobre o corpo na relação com o prazer.

Nessa direção, o preconceito nega os sentidos que traduzem essa interdição, mas, ao mesmo tempo, é a interdição que torna tão forte os efeitos sobre o sexo, que sempre encontra formas de escape, de deslize, de falha, produzindo sentido. Assim, mesmo silenciado, interditado, o dizer sobre o sexo/sexualidade continua incomodando, funcionando nas relações sociais, produzindo efeitos.

Nessa direção, o trabalho, pautado por um sistema capitalista, produz sentidos voltados para a concepção do sustento, como forma de edificação do ser humano, sem o qual o homem não se constituiria como sujeito para a sociedade, como um bom cidadão, que cumpre suas obrigações. Por essa razão, a própria relação do prazer com o trabalho fica diluída, pois não há tempo para o prazer ("tempo é dinheiro"), produzindo, assim, efeitos negativos sobre os sujeitos que visibilizam, através de sua atividade, a questão do prazer, ainda que de outrem, como é o caso da prostituta.

Portanto, tem-se, nessas condições de produção, a contradição marcada pelo trabalho e pelo prazer, ou seja, ou corpo serve para o trabalho ou serve para o prazer, o que coloca em funcionamento uma impossibilidade de que prazer e trabalho circulem mutuamente. E nessa relação, a prostituta vai se constituir como o lugar do equívoco, do deslize, pois produz um funcionamento em que trabalho e prazer se constituem mutuamente através do uso do corpo na prostituição.

Talvez essa contradição não permita que, ainda hoje, no Brasil, haja a legalização da prostituição como profissão, pois essa legalização coloca-se no lugar do interditado, do proibido, permitindo, portanto, como um de seus efeitos, a consolidação do estigma social que marca a prostituta/prostituição. Nesse entremeio, instituem-se as várias imagens projetadas sobre a prostituição que a insere, em alguns momentos, como profissão e, em outros, desqualificando-a como tal, interpretando-a como mero negócio, como veremos a seguir.

\section{O cadastro policial}

Nessas fichas encontram-se os dados básicos de um cadastro: nome, filiação, data de nascimento, cidade, nacionalidade, estado civil, identidade, residência, profissão, local de trabalho, ramo/ negócio, procedência, infração, data/entrada. Logo em seguida há um espaço denominado "Observações”, como já mencionamos.

Em alguns dos registros, encontramos profissões como costureiras, manicure, cabeleireira, etc. No caso da ficha acima (figura 1) temos como profissão "costureira" e como ramo/negócio "Atualmente, meretrício". Percebemos que há, portanto, um desencontro entre o que é profissão e o que é ramo/negócio. 


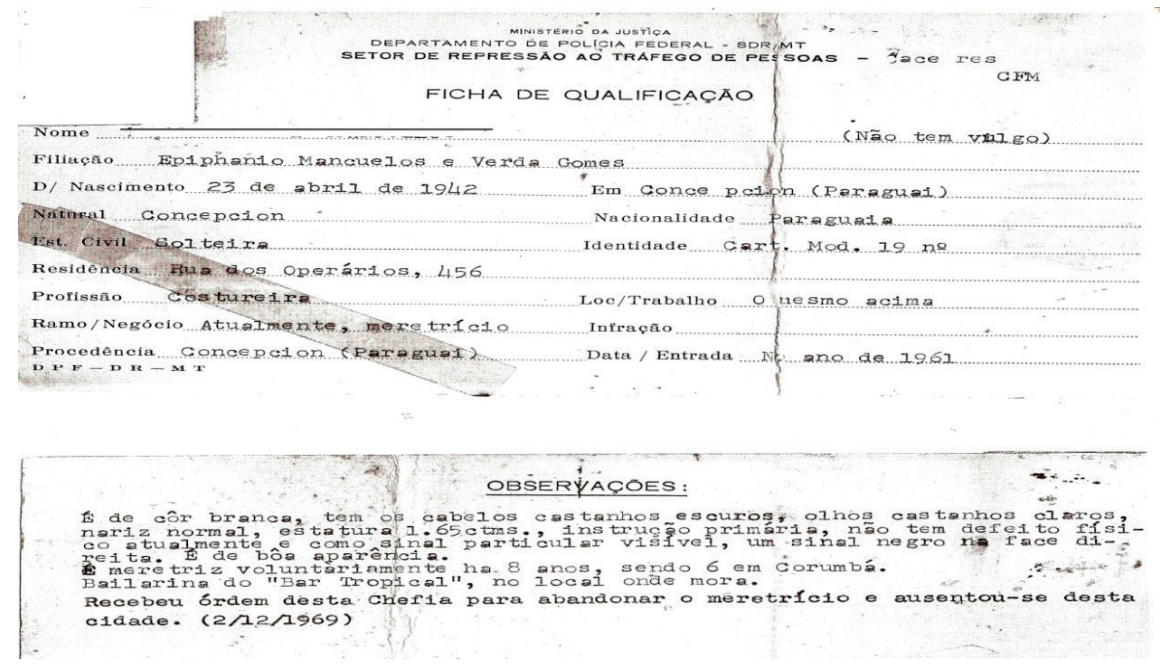

Fig. 1. Imagem adaptada de um cadastro policial com o item "observações" Fonte: Núcleo de documentação de história escrita e oral (NUDHEO)

A formulação - "Atualmente, meretrício" - produz um funcionamento em que ser meretriz é uma atividade recente, enquanto que ser costureira é uma atividade mais antiga. Essa diferença entre as formulações faz funcionar sentidos de que o sujeito possui uma profissão, mas que não atua nela ou ela é insuficiente para a manutenção própria e da família, sendo necessária a prática do meretrício, razão pela qual a ficha comporta o item profissão e o item ramo/negócio, que, no caso desse cadastro (figura 1), surgem de formas distintas.

Nesse mesmo cadastro, aparece, no item observações, uma outra profissão: a de "bailarina". Nesse item, a profissão "bailarina" juntamente com a formulação "Bar Tropical" - "É bailarina no Bar Tropical, no local onde mora" - produz um deslizamento produzindo efeitos de sentido que toma uma profissão, a de bailarina, ou um local, o bar Tropical, para significar a atividade de prostituição. Os sentidos do que se coloca como paráfrase ou polissemia dependem das condições de produção das formulações e da inscrição em cada formação discursiva na qual o sujeito do dizer se constitui. Assim, bailarina e Bar Tropical representam o espaço do meretrício no social, na cidade de Cáceres. Ou seja, estar no Bar Tropical, ser bailarina, nessas condições de produção, significa exercer a profissão de meretriz, ou seja, caracteriza a imagem da mulher como prostituta.

Conforme Orlandi (2007a), através dos objetos simbólicos, podemos compreender como o sentido é produzido, logo, é a formação discursiva que determina o que pode e deve ser dito, portanto, afirmar-se como "bailarina do Bar Tropical" insere o dizer da prostituta, enquanto materialidade, em uma formação discursiva jurídica, ou seja, aquela que autoriza a dança e o local como profissão reconhecida, silenciando a atividade da prostituição. A atividade de bailarina, então, é uma profissão socialmente 
aceita, com local e atividade definidas, o que retiraria a prostituta da ilicitude que o próprio fato de cadastrá-la produz. No entanto, a atividade de bailarina - que é considerada como profissão enquanto a prostituição é considerada ilícita - no registro policial, associada a um local - o bar Tropical - passa a ser considerada apenas uma atividade de prostituição, pois se trata da venda do próprio corpo.

Entrementes, há formulações presentes em uma outra ficha de qualificação que tomam o meretrício como profissão, tanto nos itens profissão e ramo/negócio quanto no item denominado observações, como veremos no cadastro a seguir:

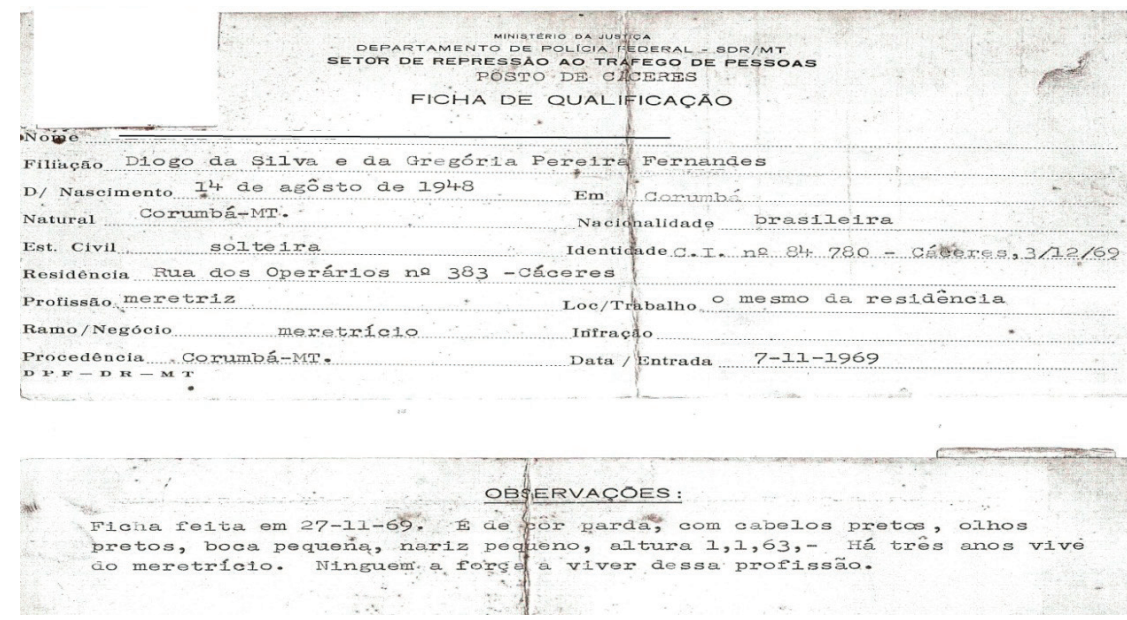

Fig. 2. Imagem adaptada de um cadastro policial com o item "observações" Fonte: Núcleo de documentação de história escrita e oral (NUDHEO)

No caso do cadastro acima (figura 2), os itens profissão e ramo/negócio representam um mesmo lugar, o do meretrício, não havendo uma distinção. Nessa direção, tem-se a inscrição do meretrício como uma profissão - "Ninguém a força a viver dessa profissão" - havendo, portanto, uma descriminalização desse tipo de atividade, que passa a ser considerada, apenas uma comercialização, como qualquer outra, em que a meretriz prestava um serviço e recebia por ele.

Vemos, portanto, como o uso do corpo para atividade de prostituição produz sentidos contraditórios, pois, considerado como degradação, o prazer para a sociedade é algo primitivo, feio, que deve ser silenciado, e a meretriz representa o que a sociedade condena e repudia, pois a sua atividade se faz pelo uso do corpo para o trabalho e pela proporção do prazer. Dessa maneira, ao dar prazer através do corpo, a prostituta pode também senti-lo, o que é negado pela sociedade capitalista, pois o corpo propicia o lugar de poder dizer sobre o trabalho e sobre o prazer, numa relação contraditória. Assim, seus efeitos produzem a contradição, tanto negativa, de estranhamento (o uso do corpo para a prostituição) quanto de aceitação pela moral social (o uso do corpo para o 
trabalho). No entanto, a prostituição também não seria o uso do corpo para o trabalho, para o sustento? E, ao mesmo tempo, não seria o corpo, nessa relação de trabalho, o objeto de proporcionar/ sentir o prazer?

Este funcionamento relaciona-se com a contradição presente nos cadastros analisados, pois as marcas presentes - "profissão: costureira; ramo/negócio: Atualmente, meretrício"; "Ninguém a força a viver dessa profissão" - demonstram o lugar da prostituição como profissão e, ao mesmo tempo, funcionam como sua denegação.

Historicamente a relação trabalho $x$ corpo constitui o corpo como lugar do sacrifício, do sustento, do viver de acordo com as regras sociais (princípio da realidade), apagando (censurando) o corpo como instrumento de prazer (princípio do prazer). $\mathrm{O}$ funcionamento inconciliável entre o princípio da realidade e o princípio do prazer, descritos por Freud (1930), marcam o lugar de ilegitimidade da prostituta/prostituição.

$\mathrm{Na}$ tentativa de controlar a sexualidade, o prazer, os regulamentaristas buscavam; entre as décadas de 1890 a 1920, não só controlar o lugar em que as prostitutas deviam viver e se prostituir, como também mantê-las sob o jugo da não satisfação sexual, ou seja, "[...] o ideal de puta para os regulamentaristas é a mulher recatada e dessexualizada, que cumpre seus deveres profissionais, mas sem sentir prazer e sem gostar de sua atividade sexual" (RAGO, 1985, p. 92). Ou seja, os efeitos produzidos são os de que as prostitutas deveriam ser "recatadas" e "dessexualizadas" ao realizarem o seu trabalho, pois lhe era interditado o prazer sexual. Desse modo, esse apagamento da possibilidade de prazer coloca a meretriz mais próxima da mulher honesta - a quem também era negado o prazer, pois sendo "recatada" e "dessexualizada", o sexo servia-lhe apenas ao propósito de gerar a prole e cuidar do lar. Nessa direção, a atividade da prostituta constituiu-se como um lugar de dar prazer e não de obter prazer, assim, a função do trabalho para a meretriz era apenas a de provê-la financeiramente, marcando a contradição constitutiva entre o trabalho e o prazer.

O uso do corpo para atividade de prostituição constituía uma forma de resistência da prostituta, pois fazia uso de algo interditado (o corpo), com o qual além de se beneficiar financeiramente, poderia sentir prazer. Os sentidos produzidos nos mostram como a interdição, a censura de falar sobre sexo, está arraigada na sociedade através desse olhar negativo sobre a relação do corpo com o prazer. Nesse sentido, o corpo não serve apenas para o trabalho, para produzir de forma a contemplar os ditames do capitalismo, uma vez que é lugar de sentir e de dar prazer. Nessa direção, a prostituta constitui-se de modo a produzir sentidos que se instalam pela contradição entre trabalho, prazer e corpo.

Trata-se de sentidos que, construídos pela moral social, produzem uma contradição que é constitutiva da prostituição, pois, 
apesar de ser renegada pela sociedade, em nenhum momento vemos a tentativa de pôr fim a essa atividade. Assim, a prostituta/ prostituição foi/é considerada um "mal necessário", devendo ser apenas controlada, mas não extinta. Aqui também se instala uma interessante contradição, pois a prostituição é mantida como um mal necessário para dar prazer ao outro, mas não para o prazer pessoal da prostituta. Dessa maneira, a prostituta é um mal necessário, pois o prazer é também necessário. Assim, se o homem não pode ter prazer com a esposa, devotada ao lar e aos filhos, é necessário alguém que lhe dê prazer, ou seja, se há, por um lado, a mulher-mãe, é preciso que haja a mulher-prostituta. Essa dualidade é historicamente constitutiva na imagem feminina e nasce da imperiosidade de o homem sentir prazer e da interdição do prazer feminino.

\section{Desejo e sobredeterminação: \\ a desresponsabilização do Estado sobre a prostituição}

A necessidade social da prostituta/prostituição se materializa nos cadastros policiais produzindo efeitos de desobrigação e de desresponsabilização do Estado:

(01) “É meretriz voluntariamente há 8 anos"

(02) "Ninguém a força a viver dessa profissão"

(03) "Não vive constrangida em sua profissão de meretriz"

Observamos que essas formulações se constituem numa relação parafrástica e polissêmica. Para Orlandi (1998), o jogo sobre as regras da língua é o que afeta a repetição, produzindo deslocamentos, que permitem, através da substituição, que o sentido possa a vir ser outro.

Nesse caso, as formulações: “É meretriz voluntariamente há 8 anos"./ "Ninguém a força a viver dessa profissão". / "Não vive constrangida em sua profissão de meretriz", produzem efeitos que apagam e subsumem todo o caráter de indução social à prostituição, pois, ao colocar a prostituição como um ato de vontade, de desejo pessoal da prostituta, apagam-se fatores socioeconômicos e culturais, produzindo o efeito de que quem pratica a prostituição voluntariamente o faz por desejo e por prazer.

Dessa maneira, a liberdade para 'escolher' se tornar meretriz, se é que ela existiu, retirou-a, por outro lado, da condição de mulher submissa e dependente, e conferiu-lhe a condição de uma mulher que é dona de sua própria vida, ou seja, a atividade de meretriz conferiu-lhe um sentido de escolha. No entanto, é preciso salientar que a posição sujeito policial interpreta as falas da prostituta, falando por ela, ao produzir as fichas. Desse modo, produz-se o silenciamento de todas as condições sociais e econômicas que levam a mulher a se prostituir, pois os efeitos que as formulações - (01) "É meretriz voluntariamente há 8 anos"; 
(02) "Ninguém a força a viver dessa profissão"; (03) "Não vive constrangida em sua profissão de meretriz" - produzem acerca da imagem das prostitutas são os de mulheres que gostam desse tipo de vida, que não se sentem culpadas e que são obstinadas em fazer o que sempre quiseram fazer. Esse efeito confere à mulher a condição de leviandade, pois optam por não mudar o que fazem e o fazem por prazer, por gosto ou por qualquer outra razão de menor valor.

Nessa direção, há uma transgressão das regras sociais, nas quais o sujeito não tem o direito de não fazer nada, ele é assujeitado ao Estado, a um sistema capitalista que preza pela produção, assim, enquanto um sujeito-de-direito, possui direitos e também deveres que condicionam o seu modo de vida. Nessa relação, o trabalho é marcado como lugar de desenvolvimento da sociedade. E se o sujeito não produz, se vive somente para o prazer, transgride todas as regras sociais, marcando sua condição na sociedade como: leviano, "vagabundo". De outro modo, para fugir a esse estigma, é necessário que sofra a interdição do prazer.

Ao se formular "É meretriz voluntariamente há 8 anos" (figura 1) - tem-se em funcionamento o sujeito de direito, aquele que "pensa" ser dono do seu dizer e do seu fazer. É, pois, esse sujeito que é ressaltado nessa formulação, pelo funcionamento do advérbio de modo "voluntariamente", que expressa o modo como se dá a prostituição, ou seja, por vontade do sujeito. Trata-se, pois, de formulações que se filiam ao discurso jurídico, uma vez que diz do sujeito-de-direito que pode, por sua livre e espontânea vontade, praticar a prostituição. O uso do vocábulo "voluntariamente" produz também o mesmo sentido que "voluntariosa", ou seja, "aquela que age apenas ou principalmente segundo sua própria vontade". O sujeito-de-direito é, nesse caso, um sujeito sem culpa, que age obstinadamente, que segue seus caprichos sem consideração à vontade de outrem para exercer a sua própria vontade, qual seja a de exercer a prostituição. Desse modo, a prostituição passa a ser atribuída à individualidade da prostituta, pois se é prostituta em razão de sua própria vontade, o que produz efeitos de desobrigação do Estado para com a prostituta/prostituição.

Nessa direção, os sentidos que se produz sobre a mulher/ meretriz, com a venda de seu próprio corpo, é o de que ela apaga a necessidade do exercício de uma profissão reconhecida em nome da sua "escolha", do seu voluntarismo, da sua ausência de culpa. O efeito que esse tipo de discurso produz é o de um sujeito que pensa ser dono de sua vontade e que pensa ser livre. É por essa razão que o seu dizer produz a ilusão de que a prostituta tem o controle sobre si e que não está sujeita às relações de poder, decorrentes dos modos de produção capitalista.

Compreendemos, assim, que há, nessa formulação, um processo de desresponsabilização do Estado, como já mostramos, pois se o sujeito policial registra que a prática da prostituição é um ato 
de vontade do sujeito, apaga, desse modo, toda a possibilidade de que ela seja decorrente das mazelas socioeconômicas das mulheres naquele período. Do mesmo modo, desresponsabiliza o aparelho repressor - a polícia - de qualquer ação, pois a prostituição não é crime, mas a indução, por terceiros, dessa prática é criminosa. Ora, se a prostituta afirma que sua ação de prostituir é voluntária, ela isenta de qualquer responsabilidade o aparelho repressor e alguém que, eventualmente, possa estar induzindo-a a tal prática.

Nas formulações (01), (02) e (03), notamos uma gradação, ou seja, são dizeres diferentes, mas que produzem os mesmos efeitos de sentido, qual seja o da não obrigatoriedade de ser meretriz. Porém, na formulação (03) - "Não vive constrangida em sua profissão de meretriz" -, além do dizer referir-se ao sujeito-de-direito, a formulação faz remissão também ao atravessamento do discurso jurídico pelo religioso, uma vez que coloca em funcionamento a noção de culpa, implicitando que a prostituta deve constranger-se da atividade que realiza. Assim, em "não vive constrangida", o funcionamento que se coloca é o de uma mulher que não se constrange, não sente culpa, não se deixa interpelar pelos sentidos instalados pela moral cristã que a prática da prostituição apaga. Trata-se de sentidos que, filiados a uma concepção da moral religiosa, colocam a mulher como alguém que deve manter-se pura, casta e desempenhando com qualidade o papel de boa mãe e esposa.

Assim, o efeito que a formulação produz é o de que as relações morais e sociais são subsumidas pelas econômicas, pois não há constrangimento pelo tipo de atividade que se pratica. Desse modo, ser meretriz, de um lado, é ter uma profissão e se colocar como produtiva em um sistema que exige a produção, daí o fato de "não viver constrangida". Mas, por outro lado, a produtividade da prostituta realiza-se sobre algo interditado - o uso do próprio corpo para a obtenção/doação de prazer -, produzindo um deslize, uma contradição, pois o uso inadequado do corpo, ressaltado pelos valores morais e instituídos pelo discurso religioso, permanece produzindo seus efeitos e afirmando o estigma social para a prostituta, mesmo que ela seja considerada produtiva, conforme a ordem do sistema capitalista.

\section{Considerações Finais}

A Classificação Brasileira de Ocupações (CBO) assegura à prostituição o status de ocupação, mas não de profissão, apesar de haver inúmeros projetos de lei que pleiteiam essa finalidade. Esse funcionamento moroso, contudo, tem uma razão de ser, pois o trabalho com o corpo deve dignificar o homem e não produzir-lhe prazer. Assim, a negação do status de profissão à prostituta funciona como um castigo, uma punição, pois as regalias conquistadas pelas profissões não devem alcançar as mulheres que usam o corpo para sentir/dar prazer. Portanto, funcionando 
por um batimento entre a paráfrase e a polissemia, há avanço e há retrocessos, há o mesmo e o diferente, há sentidos novos e sentidos recorrentes em relação às prostitutas/prostituição, pois a sua força de trabalho não pode/deve ser considerada como dignificante, mesmo com tantas ONG's, mesmo com tantos projetos de lei do legislativo, mesmo com tanta luta pela causa.

Se considerarmos os modos de funcionamento capitalista de lidar com as situações sociais, a prostituição poderia até ser elevada à condição de profissão, uma vez que, nesses modos de produção, é o lado econômico que tende a prevalecer. Contudo, é importante assinalar que o discurso que prevalece sobre a prostituta/prostituição é o da moral, o da religião, principalmente pelo poder legislativo do país que, ainda hoje, interpelado por essas discursividades moralizantes, vota contra a legalização da prostituição adulta como profissão.

Desse modo, a interdição do uso do corpo na relação com o trabalho, visando a sentir/dar prazer, produz uma contradição permanente para a prostituta, pois ela constitui-se na contramão dos valores morais e mesmo do sistema capitalista, uma vez que ela é produtiva, mas a sua forma de produção não é aceita.

Entrementes, a contradição presente na relação trabalho-corpo-prazer demonstra, ao longo da história, que, por mais que se busque restringir, censurar, interditar o prazer, ele aparece em algum lugar, sempre encontra modos de escape. É a necessidade do prazer que, em conflito com os valores morais, sociais e religiosos (princípio da realidade), propicia à prostituição seu lugar de "mal necessário", pois, o prazer é necessário, produzindo assim uma contradição constitutiva para a produção dos sentidos e dos sujeitos nas práticas de prostituição.

\begin{abstract}
This article aims to analyze the relationship between body-work-pleasure in the practices of prostitution. We question what is the work in relation to the body, which is the body in relation to work and pleasure? In this direction, we intend to address in this study the theory of Discourse Analysis of French line, which has as its theoretical object the discourse, in which we found the marks of disruption that will allow us to understand, through gestures of interpretation, as sense makes sense.
\end{abstract}

Keywords: prostitution; pleasure; profession; body. 


\section{REFERÊNCIAS}

DHOQUOIS, R. O direito do trabalho e o corpo da mulher (França: séculos XIX e XX) Proteção da produtora ou da reprodutora? In: MATOS, Maria. Izilda S, SOLHET, Rachel. O corpo feminino em debate. São Paulo: Editora UNESP, 2003.

FOUCAULT, M. História da Sexualidade I: A vontade de saber. Tradução de Maria Thereza da Costa Albuquerque e J. A. Guilhon Albuquerque. 18ª ed. Rio de Janeiro, Edições Graal, 1988.

. Vigiar e Punir: nascimento da prisão. Tradução Raquel Ramalhete. 35a ed. Petrópolis, RJ: Vozes, 2008.

. Microfísica do Poder. Rio de Janeiro: Edições Graal, 1979.

FREUD, S. O mal-estar na civilização. In: . Obras Psicológicas Completas de Sigmund Freud. Rio de Janeiro: Imago Editora LTDA, [1930] 1974.

GADET, F.; PÊCHEUX, M. A língua inatingível: o discurso na história da linguística. $2^{\mathrm{a}}$ ed. Tradução: Bethania Mariani e Maria Elizabeth Chaves de Mello. Campinas: Editora RG, 2010.

HAROCHE, C. Fazer dizer, querer dizer. Tradução de Eni Pulcinelli Orlandi com a colaboração de Freda Indursky e Marise Manoel. São Paulo: Editora HUCITEC, 1992.

LAGAZZI, S. O desafio de dizer não. Campinas, SP: Pontes, 1988.

Análise de discurso: a materialidade significante na história. In: DI RENZO (et. al.) Linguagem, História e Memória: discursos em movimento. Campinas, SP: Pontes, 2011.

ORLANDI, E. P. Paráfrase e Polissemia: A Fluidez nos Limites do Simbólico. In: RUA: Revista do Núcleo do Desenvolvimento da Criatividade da UNICAMP - NUCREDI, Campinas, SP, nº 4, mar., 1998.

Lingua e conhecimento linguístico: para uma história das ideias do Brasil. São Paulo: Cortez, 2002.

. Discurso e texto: formulação e circulação dos sentidos. $2^{\mathrm{a}} \mathrm{ed}$. Campinas, SP: Pontes, 2005.

Análise de discurso: princípios e procedimentos. $7^{\mathrm{a}}$ ed. Campinas, SP: Editora Pontes, 2007a.

. Interpretação: autoria, leitura e efeitos do trabalho simbólico. $5^{\mathrm{a}}$ ed. Campinas, SP: Pontes Editores, 2007b.

. As formas do silêncio: no movimento dos sentidos. $6^{\mathrm{a}}$ ed. Campinas, SP: Editora da Unicamp, 2007c.

PÊCHEUX, M. Semântica e discurso: uma crítica à afirmação do óbvio. Trad. Eni Puccinelli Orlandi et al. $4^{\mathrm{a}}$ ed. Campinas, SP: Editora da Unicamp, 2009.

SP: Pontes, 2008.

. O discurso: estrutura ou acontecimento. $5^{\text {a }}$ Ed. Campinas, 
PERROLT, M. Os silêncios do corpo da mulher. In: MATOS, Maria. Izilda S, SOLHET, Rachel. O corpo feminino em debate. São Paulo: Editora UNESP, 2003.

RAGO, L. M. Do cabaré ao lar: a utopia da cidade disciplinar. Brasil 1890-1930. Rio de Janeiro: Paz e Terra, 1985.

Os prazeres da noite: prostituição e códigos da sexualidade em São Paulo (1890-1930). $2^{\mathrm{a}}$ ed. Rio de Janeiro: Paz e Terra, 2008. RODRIGUES, M. T. A prostituição no Brasil contemporâneo: um trabalho como outro qualquer? In: Revista Katálysis. Florianópolis, v.12 n.1 p. 68-76 jan./jun., 2009. Disponível em: http://www.scielo. br/pdf/rk/v12n1/09.pdf. Acessado 10 fev. 2010. 